\title{
Troglitazone Increases the Number of Small Adipocytes without the Change of White Adipose Tissue Mass in Obese Zucker Rats
}

\author{
Akira Okuno, ${ }^{\star \ddagger}$ Hiroyuki Tamemoto, ${ }^{*}$ Kazuyuki Tobe, ${ }^{*}$ Kohjiro Ueki, ${ }^{*}$ Yasumichi Mori, ${ }^{\star}$ Keiji Iwamoto, ${ }^{*}$ Kazuhiko Umesono, \\ Yasuo Akanuma," Toshihiko Fujiwara," Hiroyoshi Horikoshi,§ Yoshio Yazaki, ${ }^{\star}$ and Takashi Kadowaki ${ }^{*}$ \\ *Third Department of Internal Medicine, Faculty of Medicine, University of Tokyo, Tokyo 113, Japan; ${ }^{\ddagger}$ Pharmacology and Molecular \\ Biology Research Laboratories, and ${ }^{\S}$ Research and Development, Planning and Management Department, Sankyo Co., Ltd., Tokyo 140, \\ Japan; "Graduate School of Biological Sciences, Nara Institute of Science and Technology, Nara 630-01, Japan; and "The Institute for \\ Diabetes Care and Research, Asahi Life Foundation, Tokyo 100, Japan
}

\begin{abstract}
Troglitazone (CS-045) is one of the thiazolidinediones that activate the peroxisome proliferator-activated receptor $\gamma$ (PPAR $\gamma$ ), which is expressed primarily in adipose tissues. To elucidate the mechanism by which troglitazone relieves insulin resistance in vivo, we studied its effects on the white adipose tissues of an obese animal model (obese Zucker rat). Administration of troglitazone for $\mathbf{1 5} \mathbf{d}$ normalized mild hyperglycemia and marked hyperinsulinemia in these rats. Plasma triglyceride level was decreased by troglitazone in both obese and lean rats. Troglitazone did not change the total weight of white adipose tissues but increased the number of small adipocytes $\left(<2,500 \mu \mathrm{m}^{2}\right)$ approximately fourfold in both retroperitoneal and subcutaneous adipose tissues of obese rats. It also decreased the number of large adipocytes $\left(>5,000 \mu \mathrm{m}^{2}\right)$ by $\sim 50 \%$. In fact, the percentage of apoptotic nuclei was $\sim 2.5$-fold higher in the troglitazone-treated retroperitoneal white adipose tissue than control. Concomitantly, troglitazone normalized the expression levels of TNF- $\alpha$ which were elevated by 2- and 1.4-fold in the retroperitoneal and mesenteric white adipose tissues of the obese rats, respectively. Troglitazone also caused a dramatic decrease in the expression levels of leptin, which were increased by 4-10-fold in the white adipose tissues of obese rats.

These results suggest that the primary action of troglitazone may be to increase the number of small adipocytes in white adipose tissues, presumably via PPAR $\gamma$. The increased number of small adipocytes and the decreased number of large adipocytes in white adipose tissues of troglitazone-treated obese rats appear to be an important mechanism by which increased expression levels of TNF- $\alpha$ and higher levels of plasma lipids are normalized, leading to
\end{abstract}

Address correspondence to Dr. Takashi Kadowaki, Third Department of Internal Medicine, Faculty of Medicine, University of Tokyo, 7-3-1, Hongo, Bunkyo-ku, Tokyo 113, Japan. Phone: 81-3-3875-5411 ext. 3111; FAX: 81-3-5689-7209. K. Iwamoto's current address is Discovery Research Laboratories II, Pharmaceutical Discovery Research Division, Takeda Chemical Industries, Ltd., Ibaraki 300-42, Japan.

Received for publication 18 July 1997 and accepted in revised form 8 January 1998.

J. Clin. Invest.

(c) The American Society for Clinical Investigation, Inc. 0021-9738/98/03/1354/08 \$2.00

Volume 101, Number 6, March 1998, 1354-1361

http://www.jci.org alleviation of insulin resistance. (J. Clin. Invest. 1998. 101: 1354-1361.) Key words: insulin resistance • thiazolidinedione $\bullet$ obesity $\bullet$ adipocyte $\bullet$ peroxisome proliferator-activated receptor $\gamma$

\section{Introduction}

Insulin resistance plays a major role in the pathogenesis and exacerbation of non-insulin-dependent diabetes mellitus (NIDDM). ${ }^{1}$ Obesity is the most common cause of insulin resistance, so that particularly in NIDDM associated with obesity, the alleviation of insulin resistance is the primary therapeutic target. Thiazolidinediones have been reported to improve metabolic control in human NIDDM (1-4) and animal models of NIDDM $(5,6)$ by alleviating insulin resistance. Human and animal studies have indicated that troglitazone (CS-045), one of the thiazolidinediones, enhances muscle glucose use and reduces hepatic glucose production $(3,6)$. Although troglitazone affects various points in the insulin signaling pathway $(1,7)$, the primary mechanism by which it reduces insulin resistance has not previously been identified.

At least three candidate molecules have been implicated in the development of insulin resistance due to obesity (8). Circulating lipids such as FFA, which are increased in obesity, inhibit glucose uptake and use in muscle through Randle's cycle $(9,10)$. Spiegelman and colleagues have proposed that TNF- $\alpha$ secreted by adipocytes from obese rats inhibits glucose uptake in muscle, thereby causing insulin resistance (11-13). TNF- $\alpha$ has also been reported to cause phosphorylation of insulin receptor substrate 1 on the serine residues, which inhibits insulin's signal transduction (14), or to cause downregulation of glucose transporter isoform 4 (15). Finally, the elevated leptin level itself, which is associated with obesity, may cause insulin resistance (16-18). All three hypotheses, not mutually exclusive, propose that molecules generated or secreted by hypertrophic adipocytes in obesity cause insulin resistance.

Peroxisome proliferator-activated receptor (PPAR) $\gamma$ is expressed primarily in adipose tissues $(19,20)$, and forced expression of PPAR $\gamma$ in the fibroblasts makes them differentiate into adipocytes (19). Activated PPAR $\gamma$ forms a heterodimer with retinoid $\mathrm{X}$ receptor and binds to the peroxisome proliferator responsive element, which consists of a hexameric nucleotide direct repeat of recognition motif (TGACCT) spaced by one nucleotide (21). The peroxisome proliferator responsive element has been reported to occur in the promoter region of

1. Abbreviations used in this paper: NIDDM, non-insulin-dependent diabetes mellitus; PPAR, peroxisome proliferator-activated receptor; TUNEL, terminal deoxynucleotidyl transferase-mediated dUTP nick end labeling; WAT, white adipose tissue. 
the genes encoding acyl-CoA synthase, fatty acid binding protein, lipoprotein lipase, and uncoupling protein $(22,23)$. Importantly, thiazolidinediones were found to be ligands for PPAR $\gamma$ (24). Moreover, the rank order of binding affinity of the thiazolidinediones to PPAR $\gamma$ matches closely the order of potency of their antidiabetic action, suggesting that PPAR $\gamma$ is the functional receptor of this class of compounds in their antidiabetic action $(25,26)$. Thus, it is reasonable to speculate that the primary action of thiazolidinediones is somehow to control gene expression and cellular function of adipocytes through activation of PPAR $\gamma$.

In this study, to identify molecular mechanism(s) whereby thiazolidinediones improve insulin resistance, we studied the effects of troglitazone on white adipose tissues (WATs) in obese Zucker rats, an animal model for insulin resistance associated with obesity (27). We found that troglitazone increased the population of small adipocytes in WATs, and concomitantly decreased the population of large adipocytes. This action of troglitazone appears to be an important mechanism by which increased expression levels of $\mathrm{TNF}-\alpha$ and leptin and higher levels of plasma lipids are normalized, leading to the alleviation of insulin resistance.

\section{Methods}

Animals. All the animals were purchased from Charles River Japan (Atsugi, Kanagawa, Japan). Male 7-wk-old obese ( $f a / f a$ ) Zucker rats and lean (?/+) Zucker rats were fed powder chow (F-2; Funabashi Farms, Funabashi, Japan) from the start of the experiment. The composition of the chow was as follows: $58.2 \%(\mathrm{wt} / \mathrm{wt})$ carbohydrate, $4.8 \%$ (wt/wt) fat, $20.8 \%(\mathrm{wt} / \mathrm{wt})$ protein, and $3.2 \%(\mathrm{wt} / \mathrm{wt})$ dietary fiber. 200 $\mathrm{mg} / \mathrm{kg} / \mathrm{d}$ of troglitazone was given as food admixture at the concentration of $0.2 \%$ for 4 or $19-28 \mathrm{~d}$. All the animals were killed at day 4 or 19-28 for histological preparations, or to extract total RNA from adipose tissues.

Determinations of plasma glucose, insulin, and triglyceride. Blood samples were collected from the tail vein. Plasma glucose at the end of experiment was determined with a Glucoloader-F (A \& T Co., Ltd., Tokyo, Japan) using the glucose-oxidase method. Plasma insulin was determined using an insulin RIA kit with a rat ${ }^{125}$ I-insulin assay system (Amersham International, Little Chalfont, UK) with rat insulin as standard. Plasma triglyceride was measured using determination kits (triglyceride-G-test; Wako Pure Chemical Industries, Ltd., Osaka, Japan) by the colorimetric method.

Extraction of RNA. The animals were killed by decapitation. As much fat tissue as possible was collected from the lumbar subcutaneous, retroperitoneal, epididymal, and mesenteric WATs. After measurement of wet weight, the samples were frozen quickly in liquid nitrogen and stored at $-80^{\circ} \mathrm{C}$ until extraction of total RNA. Total RNA was extracted by the standard acid guanidinium phenol-chloroform method (28) with slight modification, using $2 \mathrm{~g}$ of a tissue sample.

Probes. Probes for PPAR $\gamma$ and leptin were amplified by PCR using mouse adipose cell cDNA as template. The full-length 1518-nucleotide and 517-nucleotide cDNAs were cloned into pBluescript (Stratagene Inc., La Jolla, CA) as probes for PPAR $\gamma$ and leptin, respectively $(29,30)$. The probe for TNF- $\alpha$ was a generous gift from Dr. K. Yamada (Department of Medicine, Kurume University School of Medicine, Fukuoka, Japan). This 1,105-bp cDNA probe for TNF- $\alpha$ consists of 143 bp 5'-untranslated region, 708 bp coding region (corresponding to the entire 235 amino acid sequence), and 254 bp $3^{\prime}$-untranslated region (31). The 452-nucleotide glyceraldehyde 3-phosphate dehydrogenase probe was generated by PCR using commercially available primers (Clontech, Palo Alto, CA) with mouse liver cDNA as template and cloned into $\mathrm{pCR}^{\circledR} 2.1$ (Invitrogen Corp., Carlsbad, CA). Probes were labeled with the Megaprime ${ }^{\circledR}$ DNA la- beling system (Amersham International) using $\left[\alpha{ }^{32} \mathrm{P}\right] \mathrm{dCTP}$

$\mathrm{TBq} / \mathrm{mmol}$ ) from DuPont-NEN (Boston, MA).

Northern blot analysis. The total RNA was redissolved in a solution containing $50 \%$ formamide, $20 \mathrm{mM} 3$-( $N$-morpholino)propane sulfonic acid, $5 \mathrm{mM}$ sodium acetate, $1 \mathrm{mM}$ EDTA, $6.5 \%$ formaldehyde, $\mathrm{pH} 7.0$, then heated at $90^{\circ} \mathrm{C}$ for $5 \mathrm{~min}$ and loaded onto $1 \%$ agarose gel. 16 or $20 \mu \mathrm{g}$ of total RNA was loaded on each lane. After electrophoresis for $3 \mathrm{~h}$, the RNA was transferred to nylon membrane (Hybond $\mathrm{N}^{+}$; Amersham International) by the capillary method according to the manufacturer's instructions. After blocking, the membrane was incubated with labeled probe overnight at $42^{\circ} \mathrm{C}$ in a hybridizing buffer containing $5 \times$ Denhardt's solution, $6 \times$ SSC, $0.5 \%$ SDS, and $50 \%$ formamide, then washed twice with a solution containing $2 \times$ SSC and $0.1 \%$ SDS for $5 \mathrm{~min}$ at room temperature, and finally twice with a solution containing $0.2 \times$ SSC and $0.1 \%$ SDS for $10 \mathrm{~min}$ at room temperature. The membrane was exposed to the imaging plate of a bioimaging analyzer system (Fuji-BAS; Fuji Photo Film Co., Tokyo, Japan). Intensity of the bands was quantitated using the quantification program of the image analyzer system and expressed as an arbitrary unit.

Determinations of triglyceride and DNA in adipose tissues. For the determination of triglyceride and DNA in adipose tissues, $0.5-1 \mathrm{~g}$ of each tissue was homogenized in $10 \mathrm{ml}$ of a solution containing 150 $\mathrm{mM}$ sodium chloride, $0.1 \%$ Triton $\mathrm{X}-100$, and $10 \mathrm{mM}$ Tris, $\mathrm{pH} 8.0$, at $40-50^{\circ} \mathrm{C}$. Homogenization was performed using a polytron homogenizer (Kinematica AG, Lucerne, Switzerland) at high speed for $\sim 60 \mathrm{~s}$. $50 \mu \mathrm{l}$ of this homogenized solution was used for triglyceride determination using a determination kit (Sanassay TG-N; Sanko Pure Chemical Co., Ltd., Tokyo, Japan) by the colorimetric method. For DNA determination, the remainder of the homogenized solution was mixed with SDS, proteinase $\mathrm{K}$, and EDTA to make final concentrations of $0.1 \%, 100 \mu \mathrm{g} / \mathrm{ml}$, and $10 \mathrm{mM}$, respectively. After $1-2 \mathrm{~h}$ of incubation at $37^{\circ} \mathrm{C}$, DNA was extracted by the standard phenol-chloroform extraction method. DNA pellets were redissolved in a solution containing $10 \mu \mathrm{g} / \mathrm{ml}$ ribonuclease, $1 \mathrm{mM}$ EDTA, and $10 \mathrm{mM}$ Tris, $\mathrm{pH} 8.0$. DNA content was calculated from the absorbance of this solution at $260 \mathrm{~nm}$ as $\mathrm{OD}_{260}$ of $50 \mu \mathrm{g} / \mathrm{ml}$ DNA solution equal to 1 .

Histological analysis and morphometry. Adipose tissues were embedded immediately after decapitation in tissue-freezing medium (Tissue-Tek ${ }^{\circledR}$ OCT compound; Miles Inc., Kankakee, IL) and frozen in liquid nitrogen. Tissues were kept at $-80^{\circ} \mathrm{C}$ until use. Tissue sections ( 20 or $10 \mu \mathrm{m}$ thick) were cut in a cryostat and mounted on glass slides. Some sections after formalin fixation were stained with hematoxylin and eosin. For the quantitation of number and size of adipocytes, the sectional areas of WATs in the hematoxylin and eosinstained preparations were analyzed with an image analysis system (Q600; Leica Cambridge Ltd., Cambridge, UK). Sections of adipose tissues from rats treated for $4 \mathrm{~d}$ were fixed with $100 \%$ ethanol and stained by the terminal deoxynucleotidyl transferase-mediated dUTP nick end labeling (TUNEL) technique with a kit (In Situ Cell Death Detection Kit, POD; Boehringer Mannheim Biochemicals, Indianapolis, IN) to detect apoptotic nuclei (32). The numbers of all nuclei and apoptosis-positive stained nuclei were counted to calculate the ratio of the number of apoptotic nuclei to total number of nuclei.

Statistical analysis. Data were expressed as mean \pm SE. Biological data and mRNA expression levels were analyzed by Sheffe's and Tukey's multiple comparison tests, respectively.

\section{Results}

Improvement of plasma glucose, insulin, and lipid levels. Troglitazone caused a slight increase in the body weight of obese rats, although not statistically significant (Fig. $1 a$ ). The amount of food intake was not changed significantly by troglitazone (data not shown). While the plasma glucose level in obese control rats was only $30 \%$ higher than in lean rats, the insulin level was 19-fold higher because of severe insulin resis- 

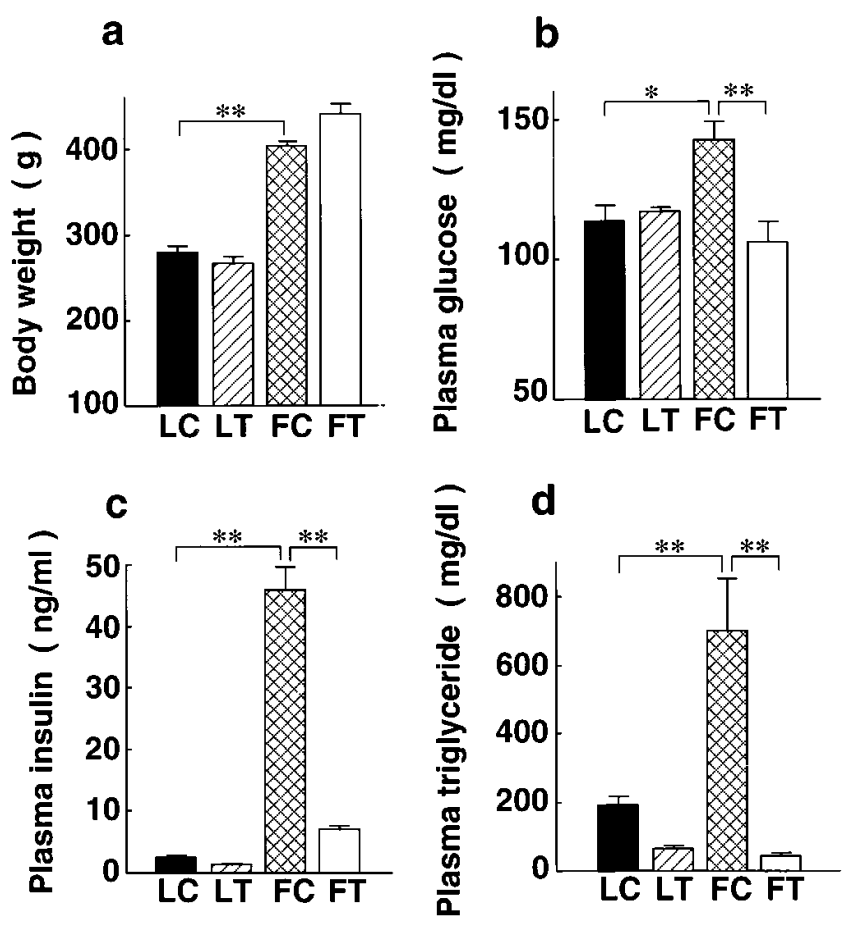

Figure 1. Body weight and plasma glucose, insulin, and triglyceride levels after troglitazone treatment. Body weight $(a)$, plasma glucose $(b)$, plasma insulin $(c)$, and plasma triglyceride $(d)$ were determined $15 \mathrm{~d}$ after troglitazone treatment. Troglitazone was given as a $0.2 \%$ food admixture. $L C$, Lean control $(n=4$, black bars). $L T$, Lean troglitazone-treated ( $n=4$, hatched bars). FC, Obese control $(n=4$, meshed bars). FT, Obese troglitazone-treated ( $n=3$, white bars). $* P<0.05,{ }^{* *} P<0.01$, Statistically significant difference.

tance. Troglitazone decreased both plasma glucose and insulin levels to levels in lean rats (Fig. 1, $b$ and $c$ ), thus improving insulin resistance in the obese animals. The plasma triglyceride level was markedly higher in obese rats. In both lean and obese rats treated with troglitazone, the triglyceride levels were decreased (Fig. $1 d$ ). The plasma FFA levels in obese rats were also determined, and troglitazone caused a marked decrease in these levels (control: $0.663 \pm 0.061$, troglitazonetreated: $0.209 \pm 0.021 \mathrm{meq} / \mathrm{liter}, P<0.01$ ).

Weight of the adipose tissues. Wet weights of WATs of obese rats were about four- to sixfold greater than of lean rats. Troglitazone did not increase significantly the total wet weight of WATs. While no decrease in WAT weight was ever seen in obese rats, in lean rats this weight tended to be reduced by troglitazone but without significance (Table I).

Expression of leptin, TNF- $\alpha$, and PPAR in WATs. We studied the effects of troglitazone or obesity itself on the expression levels of leptin. Expression levels of leptin were significantly higher in all the adipose tissues of obese rats except for epididymal WAT; in subcutaneous WAT, leptin levels reached 10-fold that in lean control rats. Troglitazone decreased dramatically the leptin levels of obese rats almost to the lean control levels in all WATs examined (Fig. 2, $a$ and $b$ ). The expression levels of leptin in lean rats were also reduced, by $\sim 20 \%$ in all WATs, although this was not statistically significant (Fig. $2 b$ ). The expression levels of TNF- $\alpha$ were increased by 2- or 1.4-fold in the retroperitoneal and mesenteric WATs of obese rats, respectively (Fig. 2, $a$ and $c$ ). Troglitazone normalized the elevated TNF- $\alpha$ levels to lean control levels (Fig. 2, $a$ and $c$ ); it also reduced the expression level of TNF- $\alpha$ by $41 \%$ in subcutaneous WATs of obese rats (Fig. $2 c$ ). Interestingly, troglitazone had almost no effect on the TNF- $\alpha$ mRNA of lean rats, and in some cases, TNF- $\alpha$ expression was even slightly increased, although not significantly, by the treatment (Fig. $2 d$ ). There was no significant change in the PPAR $\gamma$ mRNA levels with or without obesity, or with or without troglitazone (Fig. $2 d$ ). Effects of troglitazone on expression levels of leptin, TNF- $\alpha$, and PPAR $\gamma$ in obese rats were essentially identical when those results were normalized by glyceraldehyde 3-phosphate dehydrogenase levels (data not shown).

Adipocytes in the WAT. Triglyceride content contained in

Table I. Weight of WATs

\begin{tabular}{|c|c|c|c|c|c|}
\hline \multirow[b]{2}{*}{ Experimental group } & \multicolumn{5}{|c|}{ Absolute weight $(g)$} \\
\hline & Subcutaneous & Retroperitoneal & Epididymal & Mesenteric & Total \\
\hline \multicolumn{6}{|l|}{ Lean } \\
\hline control & $4.35 \pm 0.34$ & $2.42 \pm 0.27$ & $2.78 \pm 0.32$ & $1.80 \pm 0.16$ & $11.34 \pm 1.03$ \\
\hline troglitazone & $3.84 \pm 0.30$ & $1.56 \pm 0.21$ & $2.35 \pm 0.23$ & $1.22 \pm 0.12$ & $8.96 \pm 0.80$ \\
\hline \multicolumn{6}{|l|}{ Obese } \\
\hline control & $25.67 \pm 1.23$ & $10.28 \pm 0.64$ & $9.02 \pm 0.62$ & $6.05 \pm 0.21$ & $51.03 \pm 2.15$ \\
\hline \multirow[t]{2}{*}{ troglitazone } & $26.61 \pm 1.66$ & $10.79 \pm 0.33$ & $11.88 \pm 0.54]^{*}$ & $6.24 \pm 0.23$ & $55.52 \pm 2.51$ \\
\hline & \multicolumn{5}{|c|}{ Percent of body weight } \\
\hline Experimental group & Subcutaneous & Retroperitoneal & Epididymal & Mesenteric & Total \\
\hline \multicolumn{6}{|l|}{ Lean } \\
\hline control & $1.518 \pm 0.096$ & $0.843 \pm 0.082$ & $0.968 \pm 0.100$ & $0.626 \pm 0.047$ & $3.955 \pm 0.298$ \\
\hline troglitazone & $1.408 \pm 0.080$ & $0.570 \pm 0.067$ & $0.861 \pm 0.070$ & $0.447 \pm 0.032$ & $3.286 \pm 0.223$ \\
\hline \multicolumn{6}{|l|}{ Obese } \\
\hline control & $6.079 \pm 0.262$ & $2.437 \pm 0.147$ & $2.134 \pm 0.128$ & $1.436 \pm 0.059$ & $12.085 \pm 0.444$ \\
\hline troglitazone & $5.839 \pm 0.235$ & $2.373 \pm 0.020$ & $2.610 \pm 0.083$ & $1.374 \pm 0.045$ & $12.196 \pm 0.281$ \\
\hline
\end{tabular}

After troglitazone treatment for $19 \mathrm{~d}$, all rats were killed for removal of adipose tissues. Statistical significance, $* P<0.05$. 
a

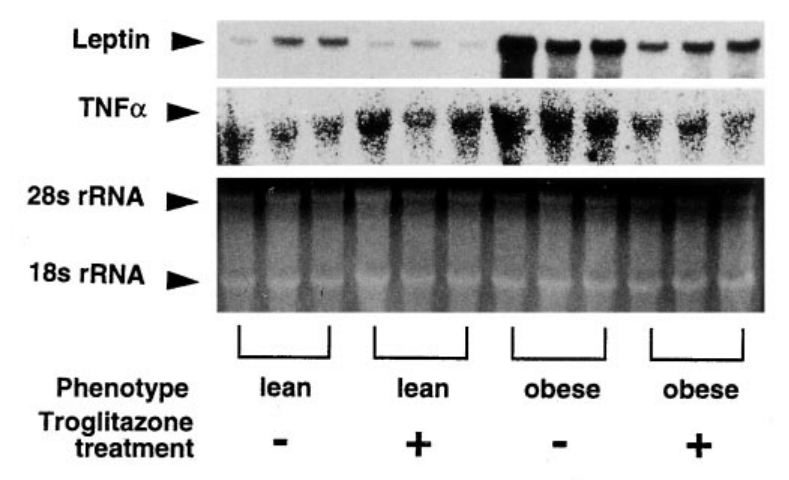

C

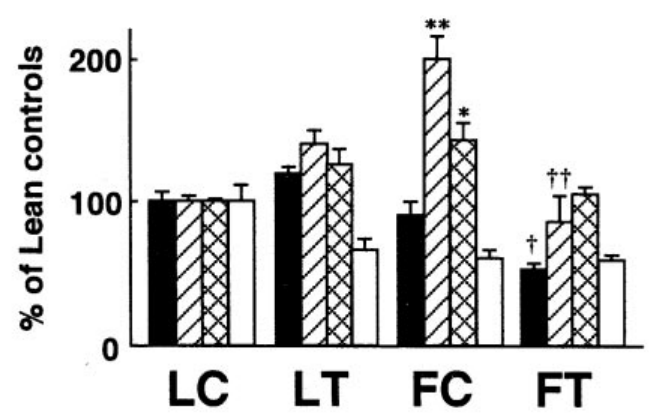

b

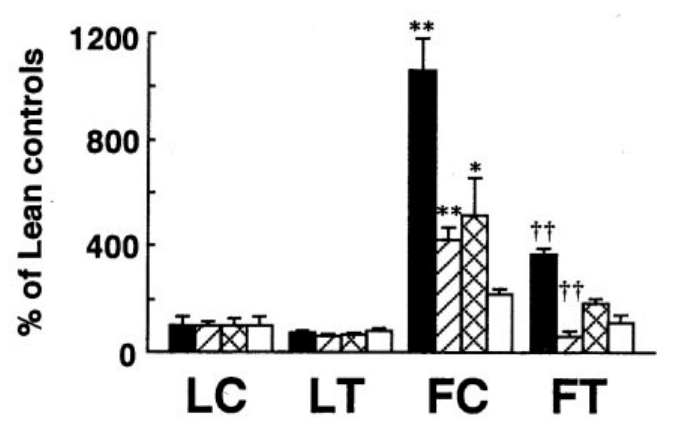

d

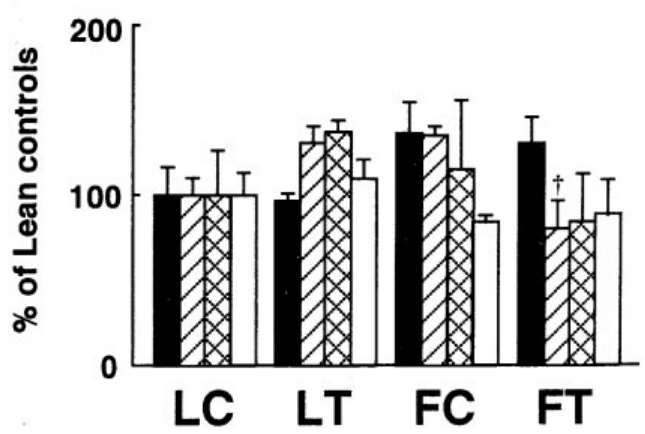

Figure 2. The mRNA expression levels of leptin, TNF- $\alpha$, and PPAR $\gamma$ in WATs. A representative Northern blot gel using leptin and TNF- $\alpha$ probes, and corresponding ethidium bromide-stained rRNA in agarose gel of mesenteric WAT $(a)$. mRNA expression levels of leptin $(b)$, TNF- $\alpha(c)$, and PPAR $\gamma(d)$ based upon the quantitation of Northern blot gels were expressed as percentage of lean control in each adipose tissue. Each of four bars represents the comparisons of subcutaneous (black bars), retroperitoneal (hatched bars), mesenteric (meshed bars), and epididymal (white bars) from left to right. Each value is mean $\pm \mathrm{SE}$ of $n=3$. $L C$, Control lean. $L T$, Troglitazone-treated lean. $F C$, Control obese. $F T$, Troglitazone-treated obese. Statistical significance, ${ }^{*} P<0.05$ or $* * P<0.01$ vs. lean control, ${ }^{\dagger} P<0.05$ or ${ }^{\dagger \dagger} P<0.01$ vs. obese control.

the whole retroperitoneal WAT was not changed (Fig. $3 a$ ). In contrast to triglyceride content, DNA content in those tissues was increased by 1.5 -fold in troglitazone-treated obese rats (Fig. $3 \mathrm{~b}$ ); this may mean that the size of adipocytes was decreased. In fact, triglyceride content per unit DNA, which was represented as milligrams of triglyceride per microgram of DNA, was decreased by troglitazone treatment in retroperitoneal WAT (Fig. 3 c). Quite strikingly, although troglitazone did not appear to affect the total mass of WATs, histological analysis revealed that troglitazone did cause a decrease in the size of adipocytes and simultaneously an increase in cell number (Fig. 4). Morphometric analysis of adipocyte distribution along with their sizes (sectional area) indicated that troglitazone increased the population of smaller-sized adipocytes and decreased the population of larger-sized adipocytes in both retroperitoneal and subcutaneous WATs (Fig. 5, $a$ and $b$ ). In a

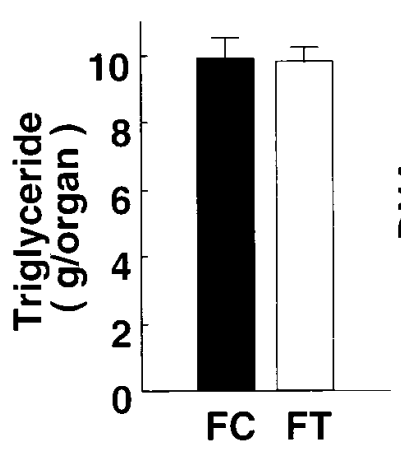

b

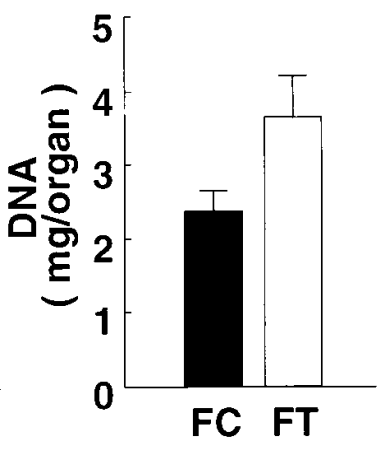

C

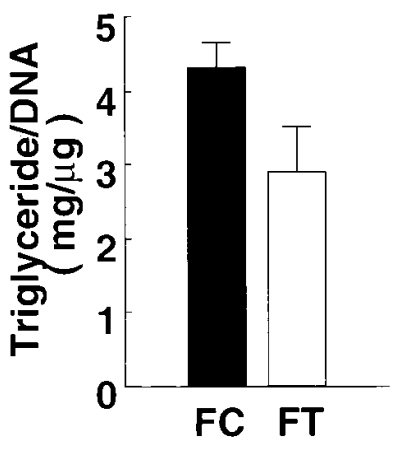

Figure 3. Triglyceride and DNA contents in retroperitoneal WATs of obese rats. Triglyceride $(a)$ and DNA $(b)$ contents were expressed as total amount contained in the whole retroperitoneal WAT, and the ratio of total triglyceride to total DNA (c) was calculated. 


\section{Control}

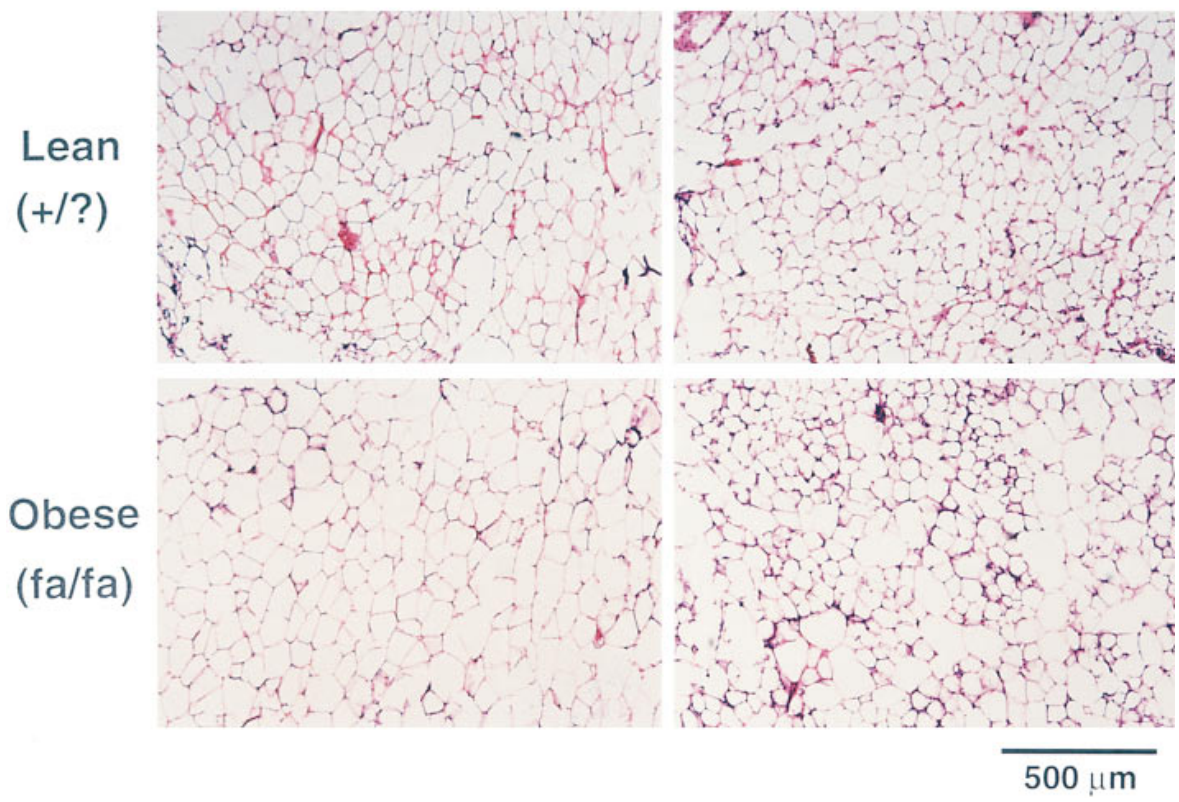

Troglitazone

Figure 4. Histology of retroperitoneal WAT. WAT sections were stained by hematoxylin and eosin after formalin fixation. All sections were cut to a thickness of $20 \mu \mathrm{m}$. The size of adipocytes from obese rats was larger than from lean rats. Troglitazone caused a decrease in the size of adipocytes in obese rats. fact, the size of white adipocytes in the troglitazone-treated obese rats $\left(2,864 \pm 163 \mu \mathrm{m}^{2}\right)$ was smaller than in obese rats without troglitazone $\left(5,031 \pm 242 \mu \mathrm{m}^{2}\right)$ in the retroperitoneal adipose tissue (Fig. 5, and Table II). Similar results were obtained in subcutaneous tissues. More importantly, the number of small adipocytes $\left(<2,500 \mu \mathrm{m}^{2}\right)$ in the $900,000 \mu \mathrm{m}^{2}$ on the adipose tissue section was increased 4.3- and 4.5-fold in troglitazone-treated obese rats compared with control obese rats (195 vs. 45 and 177 vs. 39) in the retroperitoneal and subcutaneous WAT, respectively (Fig. 5, and Table II). In contrast to the small adipocytes, the number of large adipocytes was decreased by 43 and $54 \%$ in the retroperitoneal and subcutaneous WAT, respectively, in troglitazone-treated obese rats com- pared with control obese rats. Troglitazone also caused an increase in small adipocytes and a decrease in large adipocytes in lean rats in both retroperitoneal and subcutaneous WATs, although the magnitude of this effect appeared to be less pronounced in lean than in obese rats (Figs. 4 and 5, and Table II). Similar results were also obtained in mesenteric WAT. We next examined whether troglitazone treatment affects apoptosis in adipose tissues. Although apoptotic nuclei were found in adipose tissues from both control and troglitazone-treated rats, the number of apoptotic nuclei appeared to be increased in troglitazone-treated WAT (Fig. 6). The ratio of apoptotic to total nuclear number was 10.8 and $4.3 \%$ in troglitazonetreated and control rats, respectively (Table III). a

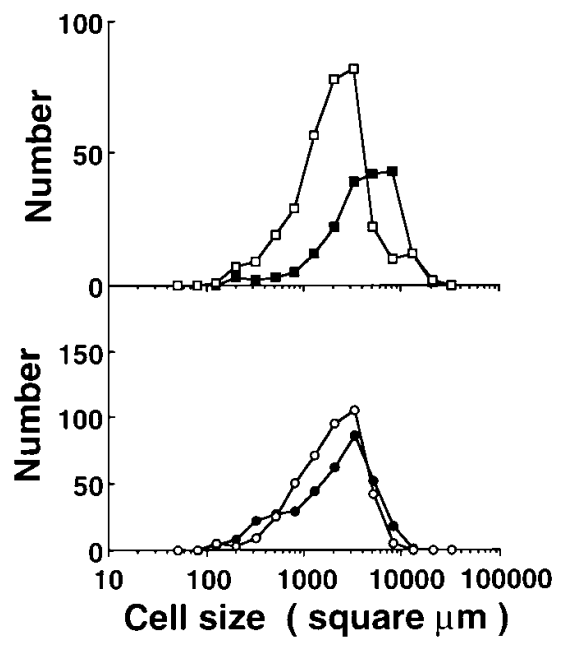

b

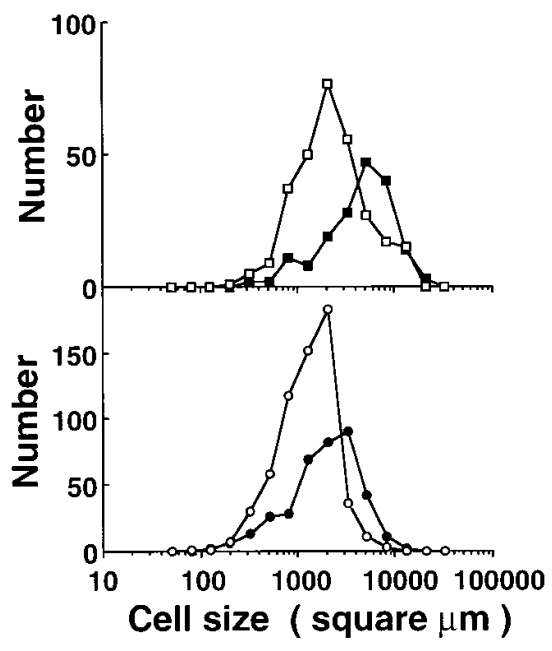

Figure 5. Distribution of sizes of white adipocytes. Number of adipocytes and their sizes in a fixed area $\left(900,000 \mu \mathrm{m}^{2}\right)$ were quantitated by an image analysis system. The representative results from retroperitoneal $(a)$ and subcutaneous adipose tissues (b). LC, Control lean (filled circles). $L T$, Troglitazone-treated lean (open circles). FC, Control obese (filled squares). $F T$, Troglitazone-treated obese (open squares). 
Table II. Morphometric Analysis of WATs

\begin{tabular}{|c|c|c|c|c|}
\hline Treatment & Number & Average size & $\begin{array}{l}\text { Small adipo- } \\
\text { cyte number } \\
\left(<2,500 \mu \mathrm{m}^{2}\right)\end{array}$ & $\begin{array}{l}\text { Large adipo- } \\
\text { cyte number } \\
\left(>5,000 \mu \mathrm{m}^{2}\right)\end{array}$ \\
\hline \multicolumn{5}{|c|}{ Retroperitoneal WAT } \\
\hline \multicolumn{5}{|c|}{ Lean } \\
\hline control & 353 & $2608 \pm 106$ & 194 & 43 \\
\hline troglitazone & 411 & $2255 \pm 70$ & $250(\times 1.3)$ & $20(\times 0.47)$ \\
\hline \multicolumn{5}{|l|}{ Obese } \\
\hline control & 184 & $5031 \pm 242$ & 45 & 81 \\
\hline troglitazone & 328 & $2864 \pm 163$ & $195(\times 4.3)$ & $35(\times 0.43)$ \\
\hline \multicolumn{5}{|c|}{ Subcutaneous WAT } \\
\hline \multicolumn{5}{|c|}{ Lean } \\
\hline control & 371 & $2485 \pm 101$ & 219 & 27 \\
\hline troglitazone & 600 & $1492 \pm 40$ & $542(32.5)$ & $8(\times 0.30)$ \\
\hline \multicolumn{5}{|l|}{ Obese } \\
\hline control & 174 & $5501 \pm 285$ & 39 & 85 \\
\hline troglitazone & 294 & $3134 \pm 173$ & $177(\times 4.5)$ & $46(\times 0.54)$ \\
\hline
\end{tabular}

Hematoxylin and eosin-stained slides were analyzed with an image analysis system. Number of adipocytes and their sizes in a fixed area $(900,000$ $\mu \mathrm{m}^{2}$ ) were quantitated.

\section{Discussion}

The major finding of this study is that troglitazone increased the adipose cell number of WATs in obese Zucker rats without affecting the total mass or the total triglyceride content of adipose tissue (Figs. 4 and 5). Morphometric analysis of the histological examination of WATs revealed that troglitazone increased the number of small adipocytes $\left(<2,500 \mu \mathrm{m}^{2}\right.$ in sectional area) by approximately fourfold (Table II). Furthermore, the total DNA content in retroperitoneal WAT was increased by 1.5 -fold (Fig. 3 ). Since the ratio of the number of adipocytes to other cells like stromal cells in the adipose tissue was reported to be $<20 \%$ (33), it is possible to estimate that the increase in the total adipocyte DNA content would reach 3.5-fold. Recently, troglitazone has been shown to be a ligand of PPARy (23-26), which is expressed specifically in adipose
Table III. The Number of Apoptotic Nuclei

\begin{tabular}{lcccc}
\hline \multicolumn{1}{c}{ Treatment } & Total count & Apoptotic nuclei & Ratio \\
\hline \multirow{4}{*}{ Control } & 1 & & & $\%$ \\
& 2 & 202 & 12 & 5.9 \\
Average & & & 8 & 2.6 \\
Troglitazone & 1 & 265 & 27 & 4.3 \\
& 2 & 320 & 36 & 10.2 \\
Average & & & & 1.3 \\
& & & & \\
\hline
\end{tabular}

After sections (10 $\mu \mathrm{m}$ thick) were stained by the TUNEL method, apoptosis nuclei were counted in a fixed area $\left(900,000 \mu \mathrm{m}^{2}\right)$.

tissues $(20,29)$. In 3T3-L1 preadipocytes, troglitazone-induced activation of PPAR $\gamma$ was shown to be associated with differentiation of preadipocytes into adipocytes (34). Thus, it has been hypothesized that troglitazone may play a key role in white adipocyte differentiation $(24,35-37)$. The increase in the number of white adipose cells by troglitazone treatment in vivo revealed in this study may be due to this stimulatory effect of troglitazone on adipocyte differentiation through PPAR $\gamma$.

Concomitantly, troglitazone-treatment appeared to cause a reduction in the number of large adipocytes, by $50 \%$ (Table II), which can explain the unaltered total mass of WAT despite the increased number of small adipocytes. Since it was reported that human adipocytes undergo apoptosis after growth factor deprivation or mild heat injury (38), we next examined whether this reduction in the number of large adipocytes was caused by increased apoptosis in response to troglitazone. In fact, the percentage of apoptotic nuclei was increased $\sim 2.5$ fold in troglitazone-treated WAT (Fig. 6, and Table III), consistent with the possibility that the reduction in the number of large adipocytes induced by troglitazone treatment may be due at least in part to increased apoptosis. Thus, we hypothesize that in WATs from troglitazone-treated rats, large adipocytes lost by apoptosis may be counterbalanced by small adipocytes that are newly differentiated by troglitazone treatment.

\section{Control}

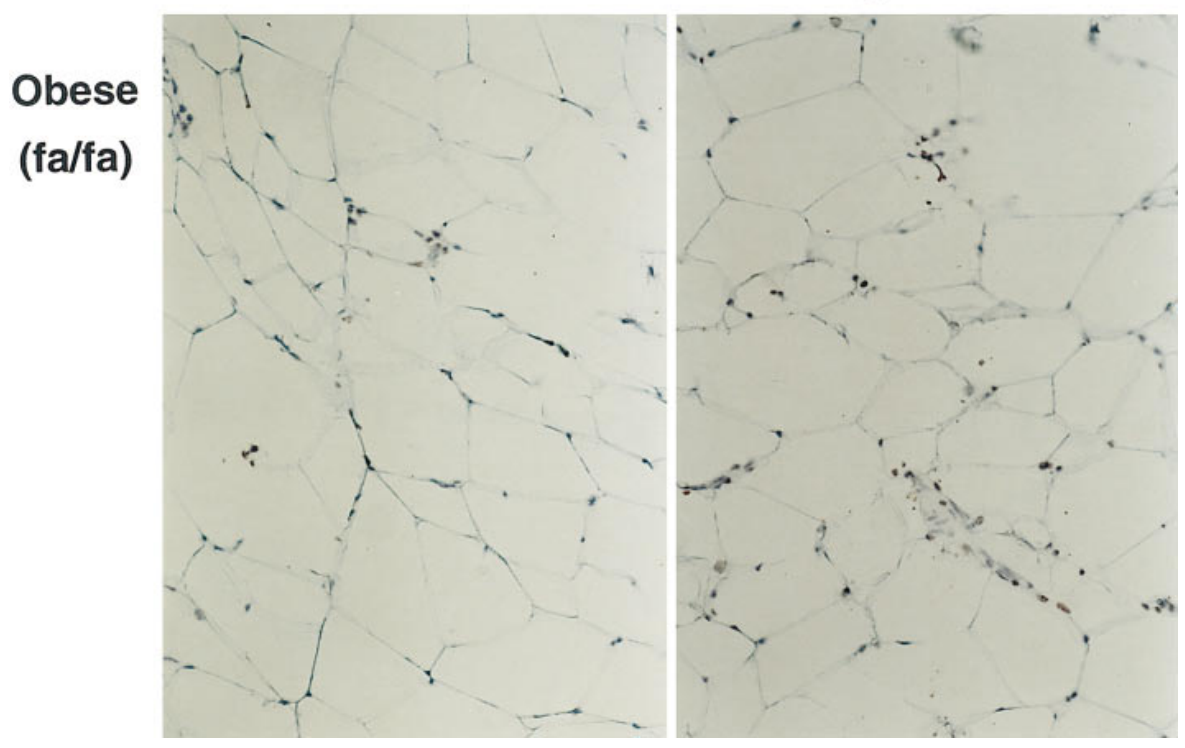

Figure 6. Apoptotic nuclei stained by the TUNEL technique. All sections were cut to a thickness of $10 \mu \mathrm{m}$. The apoptotic nuclei were stained brown. The apoptotic nuclei were found in the sections from both control and troglitazone-treated rats. The number of TUNEL-positive nuclei was much greater by troglitazone treatment than in controls. 
The number of large adipocytes $\left(>5,000 \mu \mathrm{m}^{2}\right.$ in sectional area) from obese rats increased two- to threefold compared with lean rats (Table II). Concomitantly, expression levels of leptin and TNF- $\alpha$ in WATs examined were increased in obese rats (Fig. 2, $b$ and $c$ ). We demonstrated that troglitazone treatment of obese rats resulted in a $50 \%$ decrease in the number of large adipocytes (Figs. 4 and 5, and Table II). In the same troglitazone-treated obese rats, the increased expression levels of both leptin and TNF- $\alpha$ in WATs returned to the levels of lean rats (Fig. 2, $b$ and $c$ ). Although leptin is not expressed in preadipocytes and immature adipocytes (39), it is expressed specifically in adipocytes which are fully differentiated $(30,39)$. TNF- $\alpha$ is not expressed in adipose tissue from mice with a targeted mutation in aP2, a marker for mature adipocytes (40). Moreover, the mRNA of both leptin and TNF- $\alpha$ is overexpressed in the adipose tissue of obese insulin-resistant rodents, which have hypertrophic adipocytes (Fig. $2 b$, and Table II) $(11,39$, 41). Thus, it seems that the normalization of increased expression levels of TNF- $\alpha$ and leptin by troglitazone treatment without changing fat mass may be related to the reduction in the number of large adipocytes. In in vitro studies, troglitazone is reported to directly decrease the expression of leptin by inhibiting gene transcription (42). Thus, it also seems possible that troglitazone directly inhibited the expression of TNF- $\alpha$ and leptin in large adipocytes. Since TNF- $\alpha$ has been reported to be at least partially responsible for the insulin resistance caused by obesity (11-14), it seems likely that decreased TNF- $\alpha$ levels by troglitazone contribute significantly to the improvement of muscle insulin resistance. Thiazolidinediones have been shown to affect the TNF- $\alpha$ pathway, causing insulin resistance in two ways. Thus, troglitazone reduces TNF- $\alpha$ expression in adipose tissue in vivo (43), which we have now confirmed here in obese Zucker rats (Fig. $2 c$ ), and it can also block certain actions of TNF- $\alpha$ on preadipose and adipose cell cultures $(34,35)$. Further, thiazolidinediones have been shown to reduce increased mRNA levels of leptin in obese insulinresistant animal models (44). We have been able to confirm these results in four different adipose tissues, including subcutaneous and visceral adipose tissues in obese Zucker rats (Fig. $2 \mathrm{~b}$ ). It was reported recently that leptin may cause insulin resistance especially in liver and adipocytes $(16,18)$, although this issue is still highly controversial (45); thus, it is possible that a dramatic decrease in the leptin levels by troglitazone may also contribute to amelioration of insulin resistance. Alternatively, decreased leptin levels may serve as a marker for the reduction in the number of large adipocytes.

The increased population of small white adipocytes may account for the improvement in insulin sensitivity and FFAinduced insulin resistance. Small adipocytes, which are derived from male 4-5-wk-old Sprague-Dawley rats weighing 120-160 g, can oxidize more glucose than large adipocytes derived from male 12-mo-old Sprague-Dawley rats weighing $>550 \mathrm{~g}$, in the presence of insulin (46). And small adipocytes take up more glucose than large adipocytes at submaximal levels of insulin (46). The increase in the number of small adipocytes may also account for the reduction in FFA levels after troglitazone treatment, since smaller fat cells are known to be more sensitive to the antilipolytic action of insulin (47). Thus, it seems likely that an increase in small adipocytes in WATs may contribute to lower serum FFA and triglyceride levels by thiazolidinediones $(48,49)$, which may result in amelioration of insulin resistance caused by obesity.
Subcutaneous adipose tissue may play a role distinct from that of visceral adipose tissue. In this study, we showed that in obese rats, the expression levels of leptin were higher in subcutaneous than other adipose tissues (Fig. $2 b$ ). Consistent with this, Montague et al. reported recently that the expression levels of leptin were higher in subcutaneous adipose than in omental tissue (50). We also showed that the expression levels of TNF- $\alpha$ were elevated in mesenteric and retroperitoneal but not in subcutaneous or epididymal adipose tissues (Fig. $2 c$ ). Thus, subcutaneous and visceral adipose tissues exhibit distinct patterns of gene expression, which may have precise physiological implications.

Based on the data presented in this study, we propose that the primary event triggered by troglitazone is the increase in the number of adipocytes in WATs. In the WAT, increased cell number is associated with alterations in quality of the WATs, such as an increased number of small adipocytes and a decreased number of large ones (Figs. 4 and 5, and Table II). These changes are associated with lower amounts of FFA, TNF- $\alpha$, and leptin, some of which may contribute to the improvement in insulin sensitivity.

The fact that troglitazone caused marked alterations of gene expression and cellular metabolism in adipose tissues is consistent with the fact that PPAR $\gamma$ specifically expressed in adipocytes is a major target of troglitazone. It is also important to note that alterations of adipocyte gene expression and metabolism by troglitazone were associated with alleviation of in vivo insulin resistance, supporting the concept that altered gene expression and metabolism in the hypertrophic adipose tissues may be the basis of the insulin resistance associated with obesity. This study provides a rationale for the fact that troglitazone is particularly useful and effective in insulin resistance associated with obesity.

\section{Acknowledgments}

We thank Dr. K. Yamada for his generous gift of a DNA probe for TNF- $\alpha$, and Drs. Barbara Kahn, Bradford B. Lowell, and Samuel Cushmann for helpful suggestions. We also thank Yuka Hagisawa, Eiko Yorikane, Tomoko Horiuchi, Kanako Ikeda, Kazushi Araki, and Kazumitsu Yamazaki for excellent technical assistance.

This work was supported by a grant from Uehara Memorial Foundation (to T. Kadowaki).

\section{References}

1. Iwamoto, Y., T. Kuzuya, A. Matsuda, T. Awata, S. Kumakura, G. Inooka, and I. Shiraishi. 1991. Effect of new antidiabetic agent CS-045 on glucose tolerance and insulin secretion in patients with NIDDM. Diabetes Care. 14:1083-1086.

2. Saltiel, A.R., and J.M. Olefsky. 1996. Thiazolidinediones in the treatment of insulin resistance and type II diabetes. Diabetes. 45:1661-1669.

3. Suter, S.L., J.J. Nolan, P. Wallance, B. Gumbiner, and J.Y. Olefsky. 1992. Metabolic effects of a new oral hypoglycemic agent CS-045 in NIDDM subjects. Diabetes Care. 15:193-203.

4. Kumar, S., A.J.M. Boulton, H. Beck-Nielsen, F. Berthezene, M. Muggeo, B. Persson, G.A. Spinas, S. Donoghue, S. Lettis, and P. Stewart-Long. 1996. Troglitazone, an insulin action enhancer, improves metabolic control in NIDDM patients. Diabetologia. 39:701-709.

5. Fujiwara, T., S. Yoshioka, T. Yoshioka, I. Ushiyama, and H. Horikoshi. 1988. Characterization of new oral antidiabetic agent CS-045; studies in KK and ob/ob mice and Zucker fatty rats. Diabetes. 37:1549-1558.

6. Fujiwara, T., A. Okuno, S. Yoshioka, and H. Horikoshi. 1995. Suppression of hepatic gluconeogenesis in long-term Troglitazone-treated diabetic KK and C57BL/KsJ-db/db mice. Metabolism. 44:486-490.

7. Kellerer, M., G. Kroder, S. Tippmer, L. Berti, R. Kiehn, L. Mosthaf, and H. Haring. 1994. Troglitazone prevents glucose-induced insulin resistance of insulin receptor in rat-1 fibroblasts. Diabetes. 43:447-453. 
8. Taylor, S.I., V. Barr, and M. Reitman. 1996. Does leptin contribute to diabetes caused by obesity? Science. 274:1151-1152

9. Randle, P.J., P.B. Garland, C.N. Hales, and E.A. Newsholme. 1963. The glucose fatty-acid cycle: its role in insulin sensitivity and the metabolic disturbances of diabetes mellitus. Lancet. I:785-789.

10. Boden, G. 1997. Role of fatty acids in the pathogenesis of insulin resistance and NIDDM. Diabetes. 46:3-10.

11. Hotamisligil, G.S., N.S. Shargill, and B.M. Spiegelman. 1993. Adipose expression of tumor necrosis factor- $\alpha$ : direct role in obesity-linked insulin resistance. Science. 259:87-91.

12. Hotamisligil, G.S., D.L. Murray, L.N. Choy, and B.M. Spiegelman. 1994. Tumor necrosis factor- $\alpha$ inhibits signaling from the insulin receptor. Proc. Natl. Acad. Sci. USA. 91:4854-4858.

13. Hotamisligil, G.S., A. Budavari, D. Murray, and B.M. Spiegelman. 1994. Reduced tyrosine kinase activity of the insulin receptor in obesity-diabetes. $J$. Clin. Invest. 94:1543-1549.

14. Hotamisligil, G.S., P. Peraldi, A. Budavari, R. Ellis, M.F. White, and B.M. Spiegelman. 1996. IRS-1-mediated inhibition of insulin receptor tyrosine kinase activity in TNF-alpha- and obesity-induced insulin resistance. Science. 271:665-668

15. Stephens, J.M., and P.H. Pekala. 1991. Transcriptional repression of the GLUT4 and C/EBP genes in 3T3-L1 adipocytes by tumor necrosis factor- $\alpha . J$. Biol. Chem. 266:21839-21845.

16. Cohen, B., D. Novick, and M. Rubinstein. 1996. Modulation of insulin activities by leptin. Science. 274:1185-1188.

17. Segal, K.R., M. Landt, and S. Klein. 1996. Relationship between insulin sensitivity and plasma leptin concentration in lean and obese men. Diabetes. 45: 988-991.

18. Muller, G., J. Ertl, M. Gerl, and G. Preibisch. 1997. Leptin impairs metabolic actions of insulin in isolated rat adipocytes. J. Biol. Chem. 272:1058510593.

19. Tontonoz, P., E. Hu, and B.M. Spiegelman. 1994. Stimulation of adipogenesis in fibroblasts by PPAR $\gamma 2$, a lipid-activated transcription factor. Cell. 79:1147-1156.

20. Braissant, O., F. Foufelle, C. Scotto, M. Dauca, and W. Whali. 1996. Differential expression of peroxisomal proliferator-activated receptors (PPARs): tissue distribution of PPAR- $\alpha,-\beta$, and $-\gamma$ in the adult rat. Endocrinology. 137: $354-366$.

21. Kliewer, S.A., K. Umesono, D.J. Noonan, R.A. Heyman, and R.M. Evans. 1992. Convergence of 9-cis retinoic acid and peroxisome proliferator signaling pathways through heterodimer formation of their receptors. Nature. 358 : 771-774.

22. Schoonians, K., B. Staels, and J. Auwerx. 1996. The peroxisome proliferator activated receptors (PPARs) and their effects on lipid metabolism and adipocyte differentiation. Biochim. Biophys. Acta. 1302:93-109.

23. Sears, I., M.A. MacGinntie, L.G. Kovacs, and R.A. Graves. 1996. Differentiation-dependent expression of the brown adipocyte uncoupling protein gene: regulation by peroxisome proliferator-activated receptor $\gamma$. Mol. Cell. Biol. 16:3410-3419.

24. Lehmann, J.M., L.B. Moore, T.A. Smith-Oliver, W.O. Wilkison, T.M. Willson, and S.A. Kliewer. 1995. An antidiabetic thiazolidinedione is a high affinity ligand for peroxisome proliferator-activated receptor $\gamma$. J. Biol. Chem. 270:12953-12956.

25. Willson, T.M., J.E. Cobb, D.J. Cowan, R.W. Wiethe, I.D. Correa, S.R. Prakash, K.D. Beck, L.B. Moore, S.A. Kliewer, and J.M. Lehmann. 1996. The structure-activity relationship between peroxisome proliferator-activated receptor gamma agonism and the antihyperglycemic activity of thiazolidinediones. J. Med. Chem. 39:665-668.

26. Berger, J., P. Bailey, C. Biswas, C.A. Cullinan, T.W. Doebber, N.S. Hayes, R. Saperstein, R.G. Smith, and M.D. Leibowits. 1996. Thiazolidinediones produce a conformational change in peroxisomal proliferator-activated receptor- $\gamma$ : binding and activation correlate with antidiabetic actions in $d b / d b$ mice. Endocrinology. 137:4189-4195.

27. Apweiler, A., and P. Freund. 1993. Development of glucose intolerance in obese ( $\mathrm{fa} / \mathrm{fa}$ ) Zucker rats. Horm. Metab. Res. 25:521-524.

28. Chomczynsky, P., and N. Sacchi. 1987. Single-step method of RNA isolation by acid guanidinium thiocyanate-phenol-chloroform extraction. Anal. Biochem. 162:156-159.

29. Tontonoz, P., E. Hu, R.A. Graves, A.I. Budavari, and B.M. Spiegelman. 1994. mPPAR gamma 2: tissue-specific regulator of an adipocyte enhancer. Genes Dev. 8:1224-1234.
30. Zhang, Y., R. Proenca, M. Maffei, M. Barone, L. Leopold, and J.M. Friedman. 1994. Positional cloning of the mouse obese gene and its human homologue. Nature. 372:425-432

31. Pennica, D., J.S. Hayflick, T.S. Bringman, M.A. Palladino, and D.V. Goeddel. 1985. Cloning and expression in Escherichia coli of the cDNA for murine tumor necrosis factor. Proc. Natl. Acad. Sci. USA. 82:6060-6064.

32. Gavrieli, Y., Y. Sherman, and S.A. Ben-Sasson. 1992. Identification of programmed cell death in situ via specific labeling of nuclear DNA fragmentation. J. Cell. Biol. 119:493-501.

33. Cleary, M.P., J.A. Brasel, and M.R.C. Greenwood. 1979. Developmental changes in thymidine kinase, DNA, and fat cellularity in Zucker rats. Am. $J$. Physiol. 236:E508-E513.

34. Ohsumi, J., S. Sakakibara, J. Yamaguchi, K. Miyadai, S. Yoshioka, T. Fujiwara, H. Horikoshi, and N. Serizawa. 1994. Troglitazone prevents the inhibitory effects of inflammatory cytokines on insulin-induced adipocyte differentiation in 3T3-L1 cells. Endocrinology. 135:2279-2282.

35. Szalkowski, D., S. White-Carrington, J. Berger, and B. Zhang. 1995. Antidiabetic thiazolidinediones block the inhibitory effect of tumor necrosis factor-alpha on differentiation, insulin-stimulated glucose uptake, and gene expression in 3T3-L1 cells. Endocrinology. 136:1474-1481.

36. Forman, B.M., P. Tontonoz, J. Chen, R.P. Brun, B.M. Spiegelman, an R.M. Evans. 1995. 15-deoxy- $\Delta 12,14$-prostaglandin J2 is a ligand for the adipocyte determination factor PPAR $\gamma$. Cell. 83:803-812.

37. Kliewer, S.A., J.M. Lenhard, T.M. Willson, I. Pate, D.C. Morris, and J.M. Lehmann. 1995. A prostaglandin J2 metabolite binds peroxisome proliferator-activated receptor $\gamma$ and promotes adipocyte differentiation. Cell. 83:813-819.

38. Prins, J.B., N.I. Walker, C.M. Winterford, and D.P. Cameron. 1994 Apoptosis of human adipocytes in vitro. Biochem. Biophys. Res. Commun. 201: 500-507.

39. Maffei, M., H. Fei, G.-H. Lee, C. Dani, P. Leroy, Y. Zhang, R. Proenca, R. Negrel, G. Ailhaud, and J.M. Friedman. 1995. Increased expression in adipocytes of ob RNA in mice with lesions of the hypothalamus and with mutations at the db locus. Proc. Natl. Acad. Sci. USA. 92:6957-6960.

40. Hotamisligil, G.S., R.S. Johnson, R.J. Distel, R. Ellis, V.E. Papaioannou, and B.M. Spiegelman. 1996. Uncoupling of obesity from insulin resistance through a targeted mutation in aP2, the adipocyte fatty acid binding protein Science. 274:1377-1379.

41. Pedersen, O., C.R. Kahn, and B.B. Kahn. 1992. Divergent regulation of the Glut 1 and Glut 4 glucose transporters in isolated adipocytes from Zucker rats. J. Clin. Invest. 89:1964-1973.

42. Kallen, C.B., and M.A. Lazar. 1996. Antidiabetic thiazolidinediones inhibit leptin $(o b)$ gene expression in 3T3-L1 adipocytes. Proc. Natl. Acad. Sci. USA. 93:5793-5796.

43. Hofmann, C., K. Lorenz, S.S. Braithwaite, J.R. Colca, B.J.J.R. Palzauk, G.S. Hotamisligil, and B.M. Spiegelman. 1994. Altered gene expression for tumor necrosis factor- $\alpha$ and its receptors during drug dietary modulation of insulin resistance. Endocrinology. 134:264-270.

44. Zhang, E., M.P. Graziano, T.W. Doebber, M.D. Leibowitz, S. WhiteCarrington, D.M. Szalkowski, P.J. Hey, M. Wu, C.A. Cullinan, P.L. Bailey, et al. 1996. Down-regulation of the expression of the obese gene by an antidiabetic thiazolidinedione in Zucker diabetic fatty rats and $d b / d b$ mice. J. Biol. Chem. 271:9455-9459.

45. Wang, Y., K.K. Kuropatwinski, D.W. White, T.S. Hawley, R.G. Hawley, L.A. Tartaglia, and H. Baumann. 1997. Leptin receptor action in hepatic cells. J. Biol. Chem. 272:16216-16223.

46. Olefsky, J.M. 1976. The effects of spontaneous obesity on insulin binding, glucose transport, and glucose oxidation of isolated rat adipocytes. J. Clin. Invest. 57:842-851.

47. Abbott, W.G., and J.E. Foley. 1987. Comparison of body composition, adipocyte size and glucose and insulin concentration in Pima Indian and Caucasian children. Metabolism. 36:576-579.

48. Sreenan, S., J. Sturis, W. Pugh, C.F. Burant, and K.S. Polonsky. 1996. Prevention of hyperglycemia in the Zucker diabetic fatty rat by treatment with metformin or troglitazone. Am. J. Physiol. 271:E742-E747.

49. Stevenson, R.W., N.J. Hutson, M.N. Krupp, R.A. Volkmann, G.S. Holland, J.F. Eggler, D.A. Clark, R.K. McPherson, K.L. Hall, B.H. Danbury, et al. 1990. Actions of novel antidiabetic agent englitazone in hyperglycemic hyperinsulinemic $o b / o b$ mice. Diabetes. 39:1218-1227.

50. Montague, C.T., J.B. Prins, L. Sanders, J.E. Digby, and S. O'Rahilly. 1997. Depot- and sex-specific differences in human leptin mRNA expression: implications for the control of regional fat distribution. Diabetes. 46:342-347. 